\title{
К ВОПРОСУ О ПОДХОДАХ К РАЗРАБОТКЕ ДИФФЕРЕНЦИРОВАННОЙ МЕТОДИКИ РЕГУЛИРОВАНИЯ ДЕЯТЕЛЬНОСТИ КРЕДИТНЫХ ОРГАНИЗАЦИЙ В РОССИИ
}

Таштамиров М.P. ФГБОУ ВО «Чеченский государственный университет», г. Грозный, Россия

Данная статья посвящена методикам организации дифференцированного регулирования банковской деятельности в России с учетом международных подходов. Устойчивость банковской системы зависит от механизма регулирования кредитных организаиий. Представлен обзор существуюших практик дифференцированного банковского регулирования и систематизированы основные критерии и особенности. Рассмотрен отечественный формирующийся механизм пропориионального регулирования банковской деятельности. Выявлень основные проблемные аспекты механизма регулирования. Предложен подход $к$ трансформации дифференцированного регулирования банков в России.

Ключевые слова: банковская система, дифференцированное регулирование, банковские активы, Банк России, устойчивость банковской системы.

Регулирование банковской деятельности выступает основой обеспечения устойчивости и стабильности функционирования банковской системы любой национальной экономики. Особенно остро данный вопрос стоит в условиях происходящих трансформаций и преобразований в экономических, технологических, общественных отношениях.

Регуляторные полномочия по надзору и контролю за деятельностью кредитных организаций в большинстве стран принадлежат центральному банку. В зависимости от национального банковского законодательства центральный банк самостоятельно определяет порядок и инструменты регулирования банковской деятельности. Важное значение имеет подход к осуществлению регулирования и формированию механизма по надзору и контролю за деятельностью банков. Можно выделить два основных вида банковского регулирования: плоское (экономические и правовые нормативы деятельности едины для всех банков, вне зависимости от их размера, условий функционирования, расположения, размера активов и капитала) и дифференцированное (пропорциональный подход к регулированию банков по ряду критериев и признаков).

В России с периода становления рыночных отношений произошла первая трансформация банковской системы и механизма ее регулирования, что выражалось в формировании двухуровневого типа банковского устройства. В 1986 году был принят Закон «О кооперации», который послужил правовой 
основой для создания частных акционерных коммерческих банков. Данный аспект характеризовал выделение полноценного второго уровня из распределительной банковской системы советского типа. В целях обеспечения устойчивого функционирования банковской системы РСФСР, а позднее и Российской Федерации, необходимо было создать соответствующие экономические условия, которые были реализованы установленным перечнем экономических нормативов. В 1991 году принята Инструкция № 1 «О порядке регулирования деятельности коммерческих банков» [7], устанавливающая следующие нормативы: достаточности капитала, ликвидности, минимальных размеров риска и обязательных резервов. С этого года и указанного правового акта начинается период становления регуляторной системы Центрального банка России в отношении кредитных организаций.

С самого начала формирования нормативной системы регулирования банковской деятельности было очевидно, что следует определить некоторую градацию банков для более эффективного и точечного воздействия на показатели их функционирования. В том же правовом документе были выделены три вида банков, которые подразделялись по типу организационноправовой формы, а классифицирующим признаком выступал минимальный размер уставного капитала: 0,5 млн. рублей, 5 млн. рублей и 25 млн. рублей.

Указанная градация легла в основу дифференцированного применения экономических нормативов деятельности коммерческих банков. Таким образом, в России с начала 1990-х годов была создана основа для дальнейшего формирования дифференцированного регулирования деятельности банков, где критериями выступали минимальный размер уставного капитала и организационно-правовая форма. Каждая группа банков имела свою клиентскую, операционную, функциональную, территориальную направленность.

Данное направление развития банковского регулирования было расширено в 1997 году с принятием Инструкции Банка России № 1 «О порядке регулирования деятельности кредитных организаций» [5]. Выделялось две категории банков: с размером уставного капитала до 5 млн. евро и больше 5 млн. евро. К первой категории банков относились мелкие и средние банки, как правило, регионального типа, которые ориентировались на обслуживании субъектов хозяйствования в рамках их территории расположения. Данную категорию условно стали именовать «региональные банки», хотя законодательного закрепления такого статуса не было. Для указанной группы банков применялись более низкие значения экономических нормативов. Обратная ситуация была с банками, чей капитал превышал 5 млн. евро. К этой категории относили крупные банки федерального уровня, специализировавшиеся на обслуживании крупного промышленного бизнеса страны, имеющие представительства в иностранных государствах и осуществлявших операции с инфраструктурными проектами национальной экономики и международного сотрудничества. Соответственно, нормативы деятельности для таких банков были выше. 
Дифференциация экономических нормативов по категориям банков, объясняется различным уровнем риска их деятельности, как для клиентов, так и для всей банковской системы и экономики. Более крупные банки несут в себе высокие риски, что может в последствии вызвать снижение устойчивости банковской системы, а это повлечет за собой экономические проблемы во всем народном хозяйстве, или в отдельной отрасли экономики. Крупные банки более интегрированы в экономические отношения секторов национальной экономики, и выступают кредиторами других участников финансового рынка, а значит от их устойчивости будет зависеть макроэкономическая стабильность. Соответственно, в отношении данной категории банков необходимо применять высокие требования в виде нормативов достаточности капитала и ликвидности, а также допустимого размера рисков.

Несмотря на очевидные преимущества дифференцированной методики регулирования банковской деятельности, в России с 2004 года она была заменена на плоскую систему. В Инструкции Банка России № 110-И «Об обязательных нормативов банков» [6] нет градации банков и пропорционального применения экономических нормативов. С указанной даты начинается этап однородного регулирования неоднородной банковской системы России. Следующая редакция - Инструкция Банка России № 139-И «Об обязательных нормативов банков» от 2012 года также не изменила принятую концепцию плоской системы банковского регулирования.

Наличие дифференцированного подхода к регулированию неоднородных банков в условиях высокой пространственной экономической неравномерности регионов России позволяло поддерживать приемлемую нормативную среду для устойчивого развития малых и средних банков регионального типа. Однако с переходом на плоскую систему в 2004 году наблюдается планомерное сокращение количества банков в стране (рис. 1).

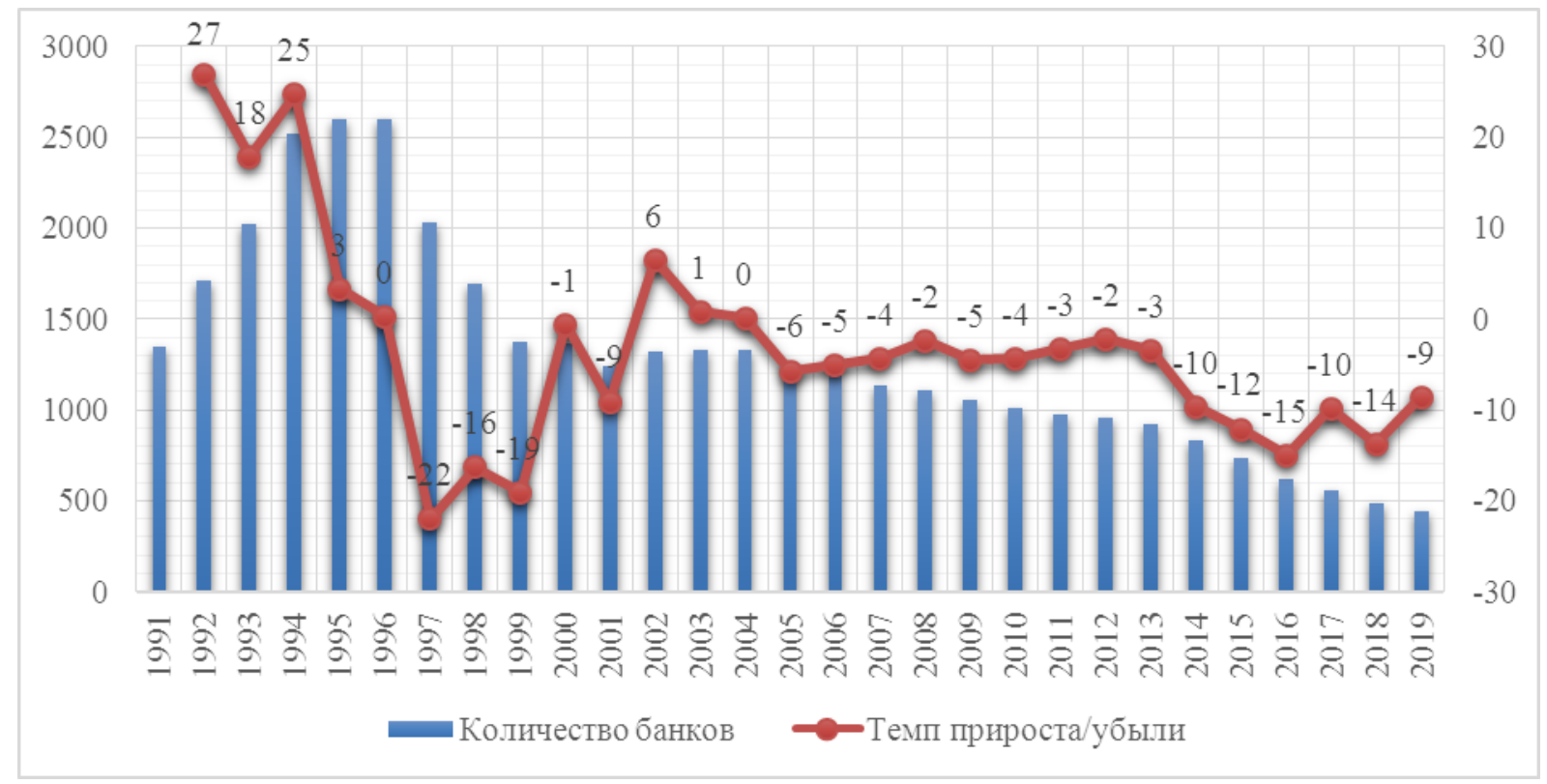

Рис. 1 - Динамика банков России за период 1991-2019 гг.

Источник: составлено автором по данным Банка Pоссии https://cbr.ru/statistics/pdko/lic/ 
Трудно сказать, насколько решающее воздействие на сокращение количества банков оказал уход Банка России от дифференцированного регулирования, но данные рисунка 1 показывают отрицательный тренд, который продолжается по сей день.

С уверенностью можно утверждать лишь то, что банки регионального типа в силу ограниченных капитальных возможностей не смогли выполнять возрастающие требования к объему собственного капитала, и как следствие, нормативу достаточности капитала. Данное обстоятельство выступает основной причиной отзыва лицензии у банка. Важно отметить, что введение количественного норматива по минимальному размеру уставного капитала в условиях колоссального разрыва между регионами страны по социальноэкономическим и финансовым показателям не является рациональным решением. Региональные банки просто не могут провести докапитализацию до необходимого значения в ограниченных региональных условиях, они вынуждены ликвидироваться или становится филиалами крупных банков федерального значения при поглощении.

Дифференцированное или пропорциональное регулирование банковской деятельности является устоявшейся практикой во множестве стран мира. В каждом отдельно взятом примере существуют различия в подходах к дефференцированному регулированию, которые выражаются в выборе критериев, закладываемых в основу такой дифференциации.

Перечень таких критериев включает:

- специализация банка (функциональная, отраслевая, клиентская, территориальная);

- финансовое состояние банка;

- качество риск-менеджмента банка;

- величина банка по объему активов и капитала;

- рейтинг банка по суммарной величине риска[4].

Обзор мирового опыта подходов к дифференцированному регулированию банковской деятельности позволил систематизировать их по основным ключевым критериям (см. табл. 1)[3; 8; 9; 10].

Таблица 1 - Подходы зарубежных стран к дифференцированному регулированию банковской деятельности

\begin{tabular}{|c|c|c|c|c|}
\hline № & Страна & $\begin{array}{c}\text { Критерии } \\
\text { дифференциации }\end{array}$ & Типы банков & Регулятор \\
\hline 1. & США & $\begin{array}{c}\text { Размер активов и } \\
\text { собственного } \\
\text { капитала, суммарная } \\
\text { величина рисков }\end{array}$ & $\begin{array}{c}\text { Национальные банки в } \\
\text { федеральном подчинении, } \\
\text { система банков штатов и } \\
\text { локальные городские банки } \\
\text { под надзором органов } \\
\text { власти штатов (плюс } \\
\text { множество } \\
\text { специализированных } \\
\text { банков и кредитно- } \\
\text { финансовых организаций) }\end{array}$ & $\begin{array}{c}\text { Федеральная } \\
\text { резервная система, } \\
\text { Комиссия по ценным } \\
\text { бумагам и биржам, } \\
\text { Управление по } \\
\text { валютному } \\
\text { контролю } \\
\text { Министерства } \\
\text { финансов, органы } \\
\text { власти штатов }\end{array}$ \\
\hline
\end{tabular}




\begin{tabular}{|c|c|c|c|c|}
\hline 2. & Германия & $\begin{array}{c}\text { Размер капитала и } \\
\text { форма собственности }\end{array}$ & $\begin{array}{c}\text { Государственные, частные } \\
\text { и кооперативные, банки } \\
\text { федеральных земель }\end{array}$ & $\begin{array}{c}\text { Федеральная служба } \\
\text { финансового } \\
\text { надзора, также все } \\
\text { банки входят в } \\
\text { саморегулируемые } \\
\text { организации } \\
\end{array}$ \\
\hline 3. & Япония & $\begin{array}{c}\text { Размер банка по } \\
\text { активам и капиталу, } \\
\text { территориальные } \\
\text { границы } \\
\text { деятельности }\end{array}$ & $\begin{array}{c}\text { Крупные национальные } \\
\text { банки, региональные } \\
\text { банки, городские банки, } \\
\text { также специализированные } \\
\text { банки по функциональному } \\
\text { назначению } \\
\end{array}$ & $\begin{array}{c}\text { Центральный банк } \\
\text { Японии, Корпорация } \\
\text { гарантии банковских } \\
\text { вкладов, } \\
\text { Министерство } \\
\text { финансов } \\
\end{array}$ \\
\hline 4. & Франция & $\begin{array}{c}\text { Размер банка и } \\
\text { уровень финансовой } \\
\text { устойчивости }\end{array}$ & $\begin{array}{c}\text { Крупные банки с } \\
\text { представительством в } \\
\text { других странах, } \\
\text { специализированные } \\
\text { банки, народные банки }\end{array}$ & $\begin{array}{c}\text { Центральный банк } \\
\text { Франции, ЕЦБ, } \\
\text { Финансовый } \\
\text { регулятор Франции }\end{array}$ \\
\hline 5. & Финляндия & $\begin{array}{c}5 \text { групп банков } \\
\text { исходя из качества } \\
\text { внутреннего контроля } \\
\text { рисков }\end{array}$ & $\begin{array}{c}\text { Национальные и } \\
\text { иностранные банки }\end{array}$ & $\begin{array}{c}\text { Центральный банк } \\
\text { Финляндии }\end{array}$ \\
\hline 6. & Швейцария & $\begin{array}{c}5 \text { категорий банков } \\
\text { исходя из объема } \\
\text { активов и активов под } \\
\text { управлением }\end{array}$ & $\begin{array}{c}\text { Глобально и национально } \\
\text { значимые банки }\end{array}$ & $\begin{array}{c}\text { Национальный орган } \\
\text { регулирования и } \\
\text { надзора над } \\
\text { финансовым рынком }\end{array}$ \\
\hline
\end{tabular}

Перечисленные страны в таблице 1 не весь список подходов к дифференцированному регулированию банковской деятельности, но они позволяют выявить основные особенности. Как видно, самым распространенным критерием дифференцированного регулирования выступает размер банка по его активам или капиталу. Второй по значимости критерий величина рисков и качество управления ими в банке. Наблюдаются отличия по концентрации регулятивных функций на уровне институтов надзора и контроля за деятельностью банков. В одних системах вся полнота регулирующих функций сосредоточена в центральном банке, в то время как в других работает смешанная система с разделением полномочий между регуляторами финансового рынка.

Во всех представленных подходах существует закрепленная законодательством кластеризация банков, которая формируется исходя из установленных критериев. Схожими особенностями представленных подходов являются инструменты, применяемые к различным категориям банков - это экономические нормативы, которые определяют требования к группам банков. Как правило, уровень требований возрастает по мере роста размера банка и суммы рисков.

Другим схожим признаком выступает децентрализации регуляторных полномочий между центральным банком и другими органами исполнительной власти. Данное обстоятельство позволяет коллегиально принимать важные решения, касательно направлений развития банковской системы через 
регуляторный механизм и комплекс принимаемых мер, а также разделить зоны ответственности между собой, соблюдая при этом баланс интересов.

В России уже много лет обсуждается необходимость разработки и внедрения дифференцированного регулирования банковской деятельности.

Первые шаги в направлении пропорционального регулирования банковской деятельности были предприняты в 2015 году с принятием Указания от 22.07.2015 № 3737-У «О методике определения системно значимых кредитных организаций» [14]. Банк России утвердил перечень системно значимых кредитных организаций в количестве 10 банков, на их долю приходится более $60 \%$ совокупных активов российского банковского сектора.

В банковской системе был выделен отдельный уровень кредитных организаций, которые отвечали требованиям системной значимости, что говорило об их особом статусе. Неустойчивость данной группы банков, оказывающих значительное влияние на всю банковскую систему и на отрасли народного хозяйства, могла негативно сказаться на стабильности и безопасности всего банковского сектора[2]. Соответственно, в целях повышения устойчивости банковской системы и выполнения требований Базель III в рамках зарубежной практики, была выделена данная группа банков. На начало 2020 года таких банков 11. Дифференцированность регулирования системно значимых банков заключается в повышении норматива достаточности капитала (H1) на:

$$
\begin{aligned}
& \text { - } \quad 0,35 \text { с } 2017 \text { года; } \\
& \text { - } \quad 0,65 \text { с } 2018 \text { года; } \\
& \text { - } \quad 1 \text { единицу за системную значимость с } 01.01 .2020 \text { года. }
\end{aligned}
$$

Вторым этапом в развитии дифференцированного регулирования банков в России было выделение двух лицензий: базовой и универсальной. С начала 2018 года для коммерческих банков при регистрации своей деятельности есть возможность выбора лицензии. Базовая лицензия позиционируется как лицензия для мелких и средних банков регионального типа с сохранением минимального размера уставного капитала в 300 млн. рублей, в то время как универсальная для более крупных кредитных организаций с капиталом выше 1 млрд. рублей.

Указанные лицензии определяют дифференцированные регулятивные требования к кредитным организациям по показателям нормативов, размера капитала, уровня риска, операционных ограничений.

Резюмировав представленные данные по категоризации банков в целях их пропорционального регулирования можно систематизировать критерии дифференциации (табл. 2).

Таблица 2 - Параметры дифференцированного регулирования банковской деятельности в России

\begin{tabular}{|c|c|c|c|}
\hline Параметр & Системно & Базовая & Универсальная \\
\hline Минимальный & Совокупные & банки & \\
размер уставного & активы группы & 300 млн. руб.-7 млрд. & 1 млрд. руб. \\
капитала, пассивов & СЗБ $>60 \%$ & рублей & \\
или активов & Объем & & \\
\hline
\end{tabular}




\begin{tabular}{|c|c|c|c|}
\hline & $\begin{array}{c}\text { привлеченных } \\
\text { средств от } \\
\text { нерезидентов } \\
\text { выше } 100 \text { млрд. } \\
\text { рублей } \\
\end{array}$ & & \\
\hline $\begin{array}{c}\text { Операционные } \\
\text { ограничения на } \\
\text { банковскую } \\
\text { деятельность }\end{array}$ & - & $\begin{array}{c}\text { Запрет на выполнение ряда } \\
\text { банковских операций с } \\
\text { нерезидентами. } \\
\text { Запрет на открытие } \\
\text { корреспондентских счетов в } \\
\text { иностранных банках. } \\
\text { Запрет на внешнее } \\
\text { фондирование }\end{array}$ & - \\
\hline $\begin{array}{l}\text { Территориальные } \\
\text { ограничения } \\
\text { деятельности }\end{array}$ & - & $\begin{array}{c}\text { Открытие структурных } \\
\text { подразделений в регионе, } \\
\text { где расположен головной } \\
\text { офис и в соседних регионах }\end{array}$ & - \\
\hline $\begin{array}{c}\text { Банковское } \\
\text { регулирование и } \\
\text { надзор }\end{array}$ & $\begin{array}{c}\text { Повышенное } \\
\text { требование к } \\
\text { нормативам } \\
\text { банковской } \\
\text { деятельности (+1): } \\
\text { Н1 - 9\% } \\
\text { Н1.1-7\% } \\
\text { Н1.2-5,5\% } \\
\text { Норматив } \\
\text { структурной } \\
\text { ликвидности Н28 - } \\
100 \%\end{array}$ & $\begin{array}{c}\text { Упрощенное - отсутствие } \\
\text { требований к выполнению } \\
\quad \text { нормативов: } \\
- \text { H1.1 } \\
- \text { H2 } \\
- \text { H4 } \\
- \text { H7 } \\
- \text { H9.1 } \\
- \text { H10.1 }\end{array}$ & $\begin{array}{c}\text { Все нормативы и } \\
\text { требования } \\
\text { обязательны }\end{array}$ \\
\hline $\begin{array}{c}\text { Управление работой } \\
\text { внутреннего } \\
\text { контроля банка }\end{array}$ & - & $\begin{array}{c}\text { Одно лицо может } \\
\text { совмещать должности и } \\
\text { функции руководителя } \\
\text { отдела управления рисками } \\
\text { и службы внутреннего } \\
\text { контроля }\end{array}$ & - \\
\hline
\end{tabular}

Источник: составлено автором на основании Ф3 «О банках и банковской деятельности» $и$ Инструкиии Банка России от 29 ноября 2019 г. N 199-И «Об обязательных нормативах и надбавках к нормативам достаточности капитала банков с универсальной лицензией»

Как видно из таблицы 2 российская практика пропорционального регулирования банков и выбор критериев дифференциации имеют отличия от зарубежных подходов, представленных в таблице 1. Отечественная методика акцентирует внимание на размере собственного капитала в абсолютном значении, несмотря на рекомендацию Базельского комитета об относительных значениях достаточности капитала как главного критерия контроля и надзора[12]. Также мировой опыт особое внимание оказывает показателям риска и качеству контроля риск-менеджмента банка. В России данный аспект не учитывается. Касательно размера активов как дифференцирующего критерия, Банк России устанавливает минимальный удельный вес активов системно значимых банков в совокупном их объеме банковской системы не 
ниже $60 \%$. Особое внимание уделено выполнению обязательных нормативов деятельности банков, которые выступают главным инструментом регулирования банковской деятельности, а также контроля и надзора.

Очевидно, что отечественный подход к дифференцированному регулированию банковской деятельности будет совершенствоваться, учитывая негативные аспекты и международный опыт. Однако следует выделить и отрицательные стороны существующей методики регулирования.

Базовая лицензия выступает фактором снижения конкурентоспособности небольшого банка, поскольку накладываемые ограничения влияют отрицательно на рентабельность активов, что в свою очередь сказывается на уровне конкуренции[1].

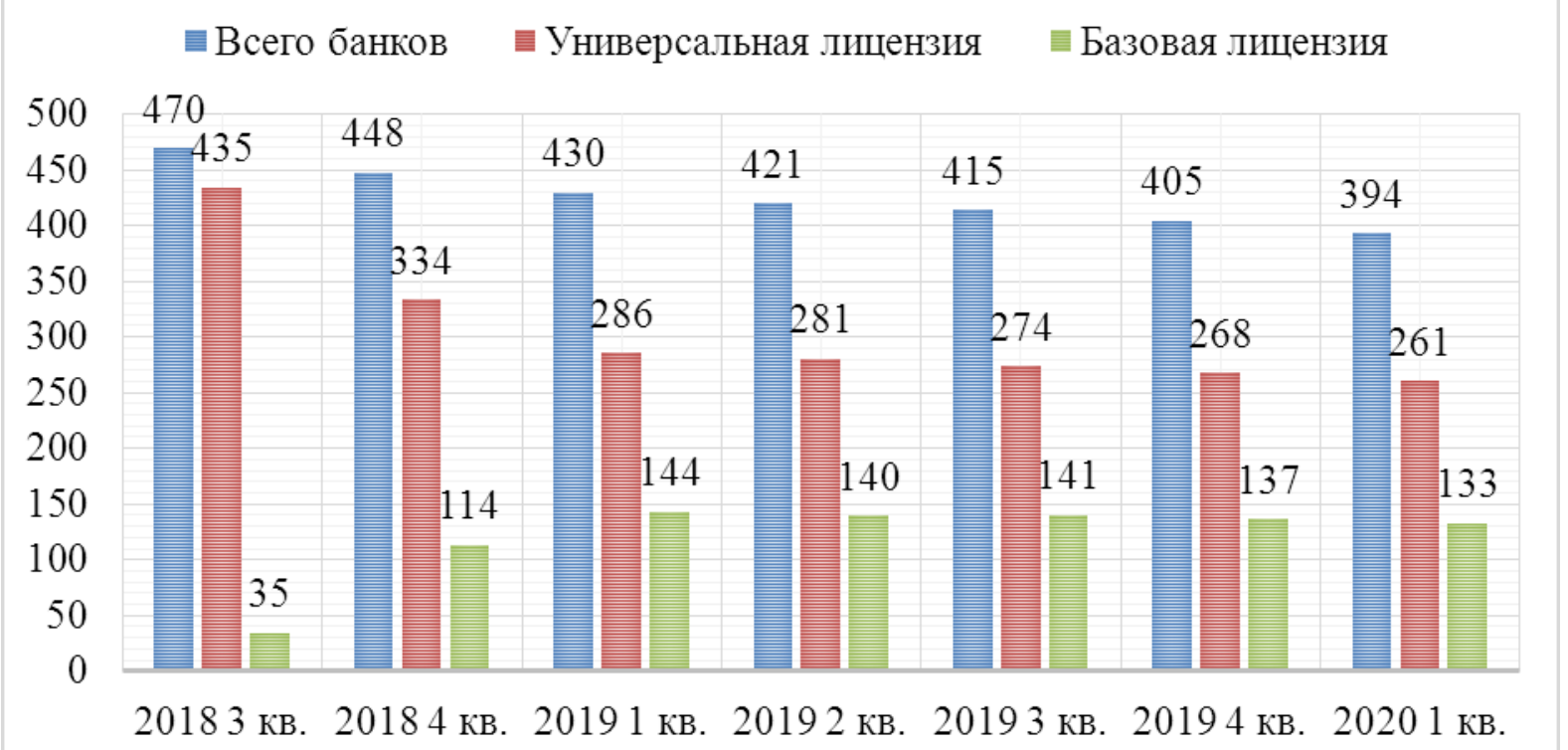

Рис. 2 Количество банков России по видам лицензий за период 3 квартал 20181 квартал 2020 гг.

После реформы по выделению двух лицензий, небольшие банки, которые не имели возможности нарастить свой собственный капитал до 1 млрд. рублей перешли на базовую лицензию. Этот процесс продолжался до начала 2019 года как показано на рисунке 2. В последующий период наблюдается сокращение количества банков с базовой лицензией более интенсивно, если рассчитывать по темпу убыли, нежели банков с универсальной лицензией. Количество ограничений, которые накладываются на банк с базовой лицензией, несмотря на послабления в выполнении обязательных нормативов банковской деятельности создают облик квази-банка, который в глазах клиентов теряет свой конкурентный уровень[13].

Дифференцированное регулирование банковской деятельности призвано обеспечить высокую устойчивость банковской системы через создание справедливых условий функционирования кредитных организаций. Неоднородная банковская система с множеством условных групп и категорий не может развиваться стабильно и эффективно выполнять свои экономические функции в условиях несовершенного механизма регулирования и надзора. 
Россия характеризуется высокой степенью пространственной экономической неравномерности, что создает множество барьеров в обеспечении качественного развития банковской системы и обеспечении ее устойчивости. Банки регионального типа, действующие в депрессивных регионах или слаборазвитых, не имеют объективных возможностей сформировать большой объем собственного капитала, чтобы соответствовать возрастающим требованиям регулятора к минимальному размеру капитала или нормативам ликвидности. И дело не в том, что такой банк неустойчив, на своем уровне финансовых возможностей и операционной деятельности он эффективен и надежен для клиентов в рамках территориального образования и выполняет свою функцию в региональном хозяйстве. Проблема заключается в том, что рассмотренные критерии дифференциации учитывают показатели банков, которые развиваются в равных условиях, но на практике все намного сложнее. Банком России не учитывается именно главная фундаментальная проблема несбалансированности банковской системы и ее неустойчивости это пространственная экономическая неравномерность и социальноэкономическая асимметрия регионов страны.

Главным дифференцирующим критерием регулирования должен выступать комплекс показателей, который будет включать в себя увязку нормативов банков с регионом, где осуществляется основная его деятельность. Среда оказывает главное влияние на кредитную организацию, следовательно, от типа региона должны зависеть и те требования, которые формируют пропорциональное регулирование банковской деятельности.

\section{Исследование выполнено при финансовой поддержке РФФИ в рамках научного проекта №18-410-200002.}

\section{Список литературы}

1. Анастасова Н.С., Дубова С.Е. Влияние ограничений бизнес-модели банков с базовой лицензией на доходность их активов и конкурентоспособность // Известия высших учебных заведений. Серия: Экономика, финансы и управление производством. - 2018.- № 1(35). - С.3-10.

2. Ведев А., Дробышевский С., Синельников-Мурылев С., Хромов М. Актуальные проблемы развития банковской системы в российской федерации // Экономическая политика. - 2014. - № 2. - С. 7-24.

3. Дубова С.Е., Домашенко А.А. Развитие механизмов стимулирующего банковского регулирования на основе концепции пропорционального регулирования и лучших зарубежных практик // Банковское дело. - 2019. - № 8 . - С. 62-67.

4. Дубова С.Е., Кутузова А.С. Дифференциация режима банковского надзора: зарубежный опыт и перспективы внедрения в России // Финансы и кредит. - 2010. - № 26 (410). - С. 15-20. 
5. Инструкция Банка России № 1 «О порядке регулирования деятельности кредитных организаций» от 01 октября 1997 года // СПС КонсультантПлюс.

6. Инструкция Банка России № 110-И «Об обязательных нормативов банков» от 16 января 2004 года // СПС КонсультантПлюс.

7. Инструкция Центрального банка РСФСР № 1 «О порядке регулирования деятельности коммерческих банков» от 30 апреля 1991 года // СПС КонсультантПлюс.

8. Кузнецова В.В. Международный опыт пропорционального банковского регулирования // Государственное управление. Электронный вестник. - 2018. - № 69. - С. 80-102.

9. Михайлов А.М., Хансевяров Р.И., Кудакова Е.С. Мировой опыт государственного регулирования банковской деятельности в условиях институциональных изменений // Экономические науки. - 2018. - № 162. - С. 27-31.

10. Морозко Н.И., Шогенова Ф.О. Международный опыт банковского надзора ФРС США и деятельность ЦБ РФ // Вестник университета. - 2016. - № 7-8. - С. 167-171.

11. Таштамиров М.Р., Вараев А.А. Системно значимые банки: современное состояние и угроза системного риска // Ученые записки Крымского инженерно-педагогического университета. - 2018. - № 2 (60). - С. 178-184.

12. Таштамиров М.Р. Место региональных банков в построении многоуровневой банковской системы России // Вестник Чеченского государственного университета. - 2019. - Т. 36. - № 4. - С. 62-66.

13. Таштамиров М.Р. Место региональных банков в современных трансформационных процессах банковского сектора России // Вестник Чеченского государственного университета. - 2019. - Т. 33. - № 1. - С. 34-41.

14. Указание Банка России от 22 июля 2015 г. N 3737-У "О методике определения системно значимых кредитных организаций" // СПС КонсультантПлюс. 